\title{
BMJ Open Prostate-specific antigen testing in inner London general practices: are those at higher risk most likely to get tested?
}

\author{
Paul Nderitu, ${ }^{1}$ Mieke Van Hemelrijck, ${ }^{2}$ Mark Ashworth, ${ }^{3}$ Rohini Mathur, ${ }^{4}$ Sally Hull, ${ }^{4}$ \\ Alexandra Dudek, ${ }^{1}$ Simon Chowdhury ${ }^{1}$
}

To cite: Nderitu $P$, Van Hemelrijck M, Ashworth M, et al. Prostate-specific antigen testing in inner London general practices: are those at higher risk most likely to get tested?. BMJ Open 2016;6:e011356. doi:10.1136/bmjopen-2016011356

- Prepublication history for this paper is available online. To view these files please visit the journal online (http://dx.doi.org/10.1136/ bmjopen-2016-011356).

Received 1 February 2016 Revised 2 May 2016 Accepted 6 June 2016

CrossMark

\footnotetext{
${ }^{1}$ Department of Oncology, Guy's Hospital, London, UK ${ }^{2}$ Cancer Epidemiology Group, Division of Cancer Studies, King's College London, London, UK

${ }^{3}$ Department of Primary Care and Public Health Sciences, King's College London,

London, UK

${ }^{4}$ Centre for Primary Care and Public Health, Queen Mary University of London, London, UK
}

Correspondence to Dr Paul Nderitu; p.nderitu@doctors.org.uk

\section{ABSTRACT}

Objectives: To investigate the association between factors influencing prostate-specific antigen (PSA) testing prevalence including prostate cancer risk factors (age, ethnicity, obesity) and non-risk factors (social deprivation and comorbidity).

Setting: A cross-sectional database of 136 inner London general practices from 1 August 2009 to 31 July 2014.

Participants: Men aged $\geq 40$ years without prostate cancer were included ( $n=150481)$.

Primary outcome: Logistic regression analyses were used to estimate the association between PSA testing and age, ethnicity, social deprivation, body mass index (BMI) and comorbidity while adjusting for age, benign prostatic hypertrophy, prostatitis and tamsulosin or finasteride use.

Results: PSA testing prevalence was 8.2\% (20132014), and the mean age was 54 years (SD 11). PSA testing was positively associated with age (OR 7074 years compared to $40-44$ years: $7.34(95 \% \mathrm{Cl} 6.82$ to 7.90 )), ethnicity (black) (OR compared to white: $1.78(95 \% \mathrm{Cl} 1.71$ to 1.85$)$ ), increasing $\mathrm{BMI}$ and cardiovascular comorbidity. Testing was negatively associated with Chinese ethnicity and with increasing social deprivation.

Conclusions: PSA testing among black patients was higher compared to that among white patients, which differs from lower testing rates seen in previous studies. PSA testing was positively associated with prostate cancer risk factors and non-risk factors. Association with non-risk factors may increase the risk of unnecessary invasive diagnostic procedures.

\section{BACKGROUND}

Prostate cancer is the commonest cancer in men in the UK with 41736 new cases in 2011 and the second commonest cause of cancer death in men in the UK with 10837 deaths in 2012. ${ }^{12}$ Known prostate cancer risk factors are increasing age, family history, ethnicity (black men) and obesity. ${ }^{2}$ Prostate cancer is rare in the under $50 \mathrm{~s}$, but

\section{Strengths and limitations of this study}

- This study features a large, inclusive general practice-registered population with representation from a wide range of ethnicity groups.

- Use of computerised general practice coded and prostate-specific antigen (PSA) data minimised information entry errors.

- This study explores the important associations between PSA testing and factors that may influence testing threshold including prostate cancer risk factors, social deprivation and comorbidity.

- This study shows an increased testing rate among black men which marks a positive change in testing behaviour compared to prior studies.

- Data on the reasoning for PSA testing were not available in this study.

the incidence rises rapidly with those aged 75-79 years at five times higher risk compared to 55-59 years old. ${ }^{2}$ Black men are reported to have a three times greater risk of developing prostate cancer compared to white men. ${ }^{4}{ }^{5}$ In the UK, the reported age-adjusted incidence rates for African Caribbeans is 647 per 100000 compared to 213 for Europeans and 199 for South Asians. ${ }^{5}$ A raised body mass index (BMI) has also been implicated as possible prostate cancer risk factor with some studies reporting a twofold increased risk in obese men. ${ }^{36}$

Currently, no prostate cancer screening programme exists in the UK and a policy for screening men aged 50-74 years every 4 years would cost an additional $£ 800$ million per annum. ${ }^{7}$ Current UK recommendations are that asymptomatic men aged over 50 who wish to have a prostate-specific antigen (PSA) test may do so after careful consideration of the implications, but general practitioners (GPs) are not encouraged to proactively raise the issue of PSA testing. ${ }^{8}$ The prostate cancer risk management 
programme, introduced in 2002, provides patients and clinicians with balanced information on the advantages and disadvantages of PSA testing and is used to help concerned men make informed decisions regarding PSA testing. ${ }^{8}$ There still remains a high degree of variability in PSA testing, with a recent qualitative study showing that GPs have varied beliefs about the risks of prostate cancer over or under diagnosis which influences the likelihood of testing. ${ }^{9}$ Therefore, PSA testing may be influenced by other factors, such as comorbidity, that are not directly associated with prostate cancer but which may be associated with the GPs' beliefs about the impact of invasive testing or diagnosis of prostate cancer.

PSA screening remains controversial and conflicting evidence exists as to the benefits of screening on prostate cancer mortality. While the European Randomised Study of Screening for Prostate Cancer showed a reduced mortality rate in patients undergoing PSA screening, ${ }^{10}$ the US Prostate, Lung, Colorectal and Ovarian (PLCO) trial showed no statistically significant difference in mortality rates. ${ }^{11}$ However, the PLCO study had a higher contamination rate in the control group with $45 \%$ of patients having had an opportunistic PSA test in the 3 years prior to study randomisation. ${ }^{11}$ The PSA test has poor specificity in regards to prostate cancer diagnosis with up to $76 \%$ of men having a falsely raised PSA level. ${ }^{7}$ Moreover, the large number of men screened for prostate cancer have local or indolent disease and up to $84 \%$ of men diagnosed with prostate cancer survive 10 years or more; ${ }^{2} 10^{12} 13$ hence, the risk of unnecessary invasive diagnostic or treatment strategies with associated harmful side effects such as sexual dysfunction and incontinence is ever present. ${ }^{10} 12{ }^{13}$ Conversely, prostate cancer remains the second commonest cause of cancer death in men in the UK and earlier diagnosis and treatment, especially in some patients with aggressive disease could reduce morbidity and mortality. ${ }^{12}$ Moreover, active surveillance is used as an initial management option for some patients with low risk prostate cancer reducing the negative risks of invasive treatment. ${ }^{12}$

The PSA testing rate per year in the UK is estimated to be $\sim 6 \%$ in men aged 45-89 years and remained unchanged between 2004 and 2011. ${ }^{14}{ }^{15}$ PSA testing has previously been reported to vary with increasing age, ethnicity (decreased in black patients), geographical location, social deprivation, decision tool use and test indication. ${ }^{14-16}$ However, previous studies have relied upon self-reported data ${ }^{16}$ or have had a restrictive age inclusion criteria. ${ }^{14}{ }^{15}$ Moreover, previous studies have not fully explored the influence of ethnicity in detail ${ }^{14}$ nor investigated the possible influence of comorbidity on PSA testing. The aim of this study is to investigate the association between PSA testing prevalence and factors that may influence testing including prostate cancer risk factors (age, ethnicity and obesity) and non-risk factors of social deprivation and comorbidity.

\section{METHODS}

\section{Study data and setting}

Data for the study were taken from the inner east London boroughs of Newham, City and Hackney and Tower Hamlets and covered $>95 \%$ of the general practice-registered population. Routine clinical data were entered on practice computers using EMIS Web software. Anonymised Read coded clinical and prescription data recorded over a 5-year period were extracted from 136 participating practices in July 2014. Data were managed according to the UK National Health Service information governance requirements and ethical approval was not required for this anonymised observational study.

\section{Participant selection}

We included all male patients aged $\geq 40$ years on 31 July 2014. Patients with a recorded history of prostate cancer ever were excluded as PSA testing in this setting would be for monitoring purposes and not for the detection of incident cases. Data from 150481 patients were included in the cross-sectional study as shown in figure 1.

\section{PSA measurement}

The latest PSA measurement per patient recorded during the 5-year study period was used to categorise patients into tested and untested PSA groups; free and total PSA measurements were included. Patients with a PSA measurement were categorised into 0-0.99, $1-3.99, \quad 4-9.99$ and $\geq 10 \mathrm{ng} / \mathrm{mL}$ groups. The PSA testing prevalence was calculated as the percentage of tested study participants over the 5-year and 1-year (August 2013-2014) period. Data on the reasoning for PSA testing were not available in this study.

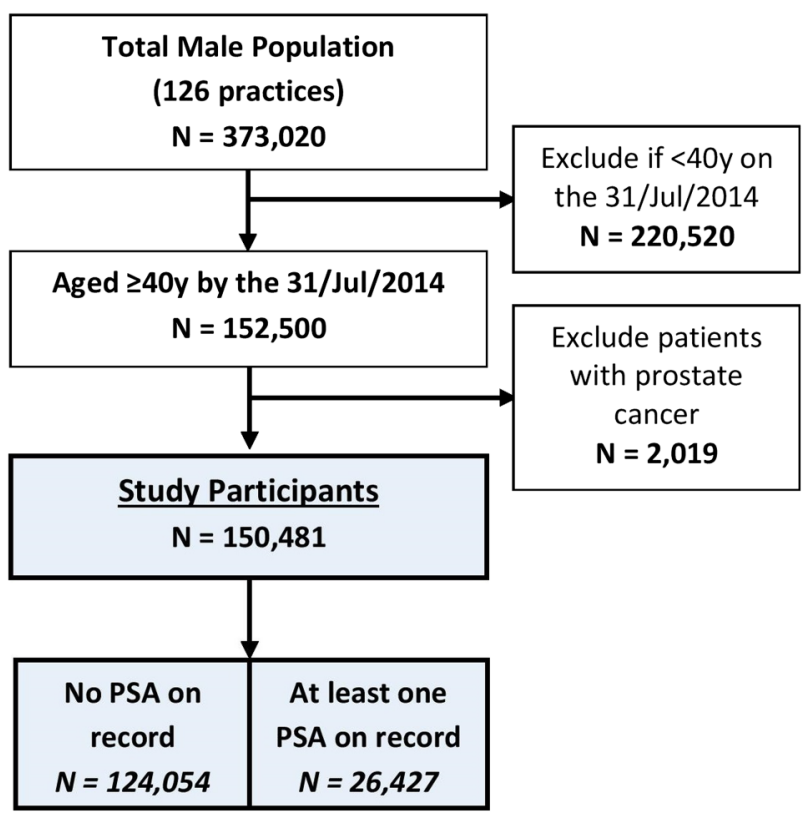

Figure 1 PSA testing study selection flow chart. PSA, prostate-specific antigen. 


\section{Study cofactors}

\section{Sociodemographics}

Data on patient age, ethnicity and individual-level Townsend score (calculated using patient postcodes) as a measure of deprivation were extracted. The Townsend score is a census-based measure of deprivation and is widely used to assess deprivation in the UK. ${ }^{17}$ Patients were categorised into 5-year age groups and were placed into approximate deprivation quintiles based on the relative Townsend scores; $272(0.18 \%)$ patients did not have a Townsend score on record. Ethnicity was selfreported by patients during practice visits and recorded using 2001 UK census ethnicity codes. For the purposes of this study, ethnic groups were grouped into white (British, Irish, other white), black (African, Caribbean, other black), mixed black, South Asian (Indian, Pakistani, Bangladeshi, other Asian), Chinese, mixed Asian, other mixed and other ethnicity. Those without a recorded ethnicity were categorised as 'not defined' and included in the analysis. There were 13149 patients $(8.7 \%)$ without a recorded ethnicity.

\section{Body mass index}

Data on the BMI $\left(\mathrm{kg} / \mathrm{m}^{2}\right)$ were extracted for the study period with the latest BMI used to categorise patients. Patients were categorised into normal weight (18.524.9), underweight $(<18.5)$, overweight $(25-29.9)$, obese class I (30-34.9), class II (35-39.9) and class III $(\geq 40)$ groups. There were $11462(7.6 \%)$ patients without a recorded BMI.

\section{Comorbidity}

Comorbidities included in this study were placed into four disease clusters.

1. The cardiovascular cluster, which included ischaemic heart disease, peripheral vascular disease, heart failure and atrial fibrillation grouped together as cardiovascular disease (CVD). Hypertension (HTN), type I and II diabetes mellitus (DM), chronic kidney disease (stages 3-5) and stroke/transient ischaemic attack were also individually included in the cardiovascular cluster.

2. The respiratory cluster, which included asthma and chronic obstructive pulmonary disease.

3. The mental health cluster, which included dementia and serious mental illness (SMI). SMI group included schizophrenia, bipolar disorder, mania and psychosis.

4. Other cancer (excluding prostate cancer).

The selected comorbidities were chosen as they were all Quality Outcome Framework (HSCIC, 2014)-related domains, hence were well recorded and represented prevalent, clinical conditions that GPs may take into consideration when deciding upon the appropriateness of PSA testing. Presence of the select comorbidities was identified from the data using unique clinical codes (Read codes) used in UK general practice data coding.

\section{Adjusted covariates}

Presence of benign prostatic hypertrophy (BPH) or prostatitis was defined as a diagnosis existing at any point throughout the patient records. Data on tamsulosin or finasteride use, used for the treatment of symptomatic $\mathrm{BPH}$, were also extracted and were defined as the issue of a prescription at any point during the 5-year study period. BPH and prostatitis symptoms and presentation overlap with those of prostate cancer, which may prompt PSA testing, hence their inclusion. Similarly, finasteride and tamsulosin, used for the treatment of $\mathrm{BPH}$, influence PSA levels or disease symptomology, hence may influence the decision to undertake PSA testing.

\section{Statistical methods}

Normally distributed continuous variables were analysed as means and SDs, and dichotomous variables were analysed as counts and percentages. Parametric tests for significant differences were determined using unpaired t-test or $\chi^{2}$ test as appropriate.

Logistic regression analyses, with $95 \%$ CIs, were used to assess the association between the odds of PSA testing and age, ethnicity, deprivation quintile, BMI and comorbidity (the comorbidity cluster and individual comorbidities were tested). The $40-44$ years, white, least deprived quintile, normal weight, absence of the comorbidity cluster or individual comorbidity acted as the reference for the aforementioned cofactors. Two adjusted models were derived per cofactor analyses: (1) an age-adjusted model and (2) an age-adjusted and covariate-adjusted (BPH, prostatitis, tamsulosin or finasteride use) model. All statistical analyses were carried out on SPSS, V.20.0 (IBM, USA).

\section{RESULTS}

Characteristics of PSA tested and untested patients

The prevalence of PSA testing over the previous 5 years was $17.6 \%$ ( $n=26427$, practice IQR 12.2-20.3\%) for male patients aged $\geq 40$ years. The 1 year PSA testing prevalence (1 August 2013-31 July 2014) was $8.2 \%$ ( $\mathrm{n}=11065$, practice IQR 4.8-9.7\%). The mean age of included patients was 53.6 years (SD 11.4). Over $66 \%$ were classified as overweight or obese and a significant proportion had HTN (25.5\%), DM (15.6\%) or CVD $(9.1 \%)$. There were significant differences in the age, ethnicity, social deprivation, BMI, comorbidity and covariate status between PSA tested and untested patients $(\mathrm{p}<0.001$, table 1$)$.

\section{PSA testing prevalence, level and age}

As shown in figure 2A, the PSA testing prevalence increased significantly with age from $5.1 \%$ at age $40-44$ years to $39.7 \%$ at age $70-74$ years $(p<0.001)$. However, the greatest proportion of PSA tests performed occurred in patients aged $55-59$ years $(16.1 \%)$ with just $7 \%$ of all PSA tests performed in patients aged 70-74 years.

The PSA level rose significantly with age, with $0.8 \%$ of patients aged 40-44 years having a PSA level of $4 \mathrm{ng} / \mathrm{mL}$ 
Table 1 Baseline characteristics of PSA tested and untested patients

\begin{tabular}{|c|c|c|c|c|}
\hline Baseline characteristics & $\begin{array}{l}\text { All } \\
(n=150481)\end{array}$ & $\begin{array}{l}\text { PSA untested } \\
(n=124054)\end{array}$ & $\begin{array}{l}\text { PSA tested } \\
(n=26427)\end{array}$ & p Value* \\
\hline \multicolumn{5}{|l|}{ Prostate cancer risk factors } \\
\hline Age, mean (SD) & $53.6(11.4)$ & $52.1(10.7)$ & $60.8(11.9)$ & $<0.001$ \\
\hline \multicolumn{5}{|l|}{ Ethnicity, \% (N) } \\
\hline White & $40.9(61621)$ & $41.0(50897)$ & $40.6(10724)$ & \multirow[t]{9}{*}{$<0.001$} \\
\hline Black & $17.2(25956)$ & $16.0(19835)$ & $23.2(6121)$ & \\
\hline South Asian† & 26.1 (39 341) & 26.5 (32 858) & $24.5(6483)$ & \\
\hline Chinese & $0.9(1363)$ & $1.0(1200)$ & $0.6(163)$ & \\
\hline Mixed black & $1.5(2299)$ & $1.3(1647)$ & $2.5(652)$ & \\
\hline Mixed Asian† & $0.2(235)$ & $0.2(195)$ & $0.2(40)$ & \\
\hline Other mixed & $0.4(608)$ & $0.4(535)$ & $0.3(73)$ & \\
\hline Other ethnicity & $3.9(5909)$ & $3.9(4857)$ & $4.0(1052)$ & \\
\hline Not specified & 8.7 (13 149) & 9.7 (12 030) & $4.2(1119)$ & \\
\hline \multicolumn{5}{|l|}{ BMI class $\ddagger, \%(\mathrm{~N})$} \\
\hline Normal weight & $31.6(47619)$ & $35.4(40$ 140) & 29.1 (7479) & \multirow[t]{6}{*}{$<0.001$} \\
\hline Underweight & $1.0(1558)$ & $1.2(1321)$ & $0.9(237)$ & \\
\hline Overweight & 39.1 (58 787) & $42.0(47614)$ & $43.5(11173)$ & \\
\hline Obese class I & 15.3 (22 985) & 15.9 (17 993) & $19.4(4992)$ & \\
\hline Obese class II & $4.0(6026)$ & 4.1 (4653) & $5.3(1373)$ & \\
\hline Obese class III & $1.4(2044)$ & $1.4(1586)$ & $1.8(458)$ & \\
\hline \multicolumn{5}{|l|}{ Non-risk factors } \\
\hline \multicolumn{5}{|l|}{ Deprivation§, \% (N) } \\
\hline Least deprived & $21.8(32780)$ & 21.5 (26 646) & $23.2(6134)$ & \multirow[t]{5}{*}{$<0.001$} \\
\hline Q2 & $16.6(25022)$ & $16.6(20519)$ & 17.1 (4503) & \\
\hline Q3 & 17.1 (25 802) & $17.2(21253)$ & $17.2(4549)$ & \\
\hline Q4 & $19.0(28637)$ & 19.1 (23 654) & 18.9 (4983) & \\
\hline Most deprived & 25.2 (37 968) & $25.6(31748)$ & $23.6(6220)$ & \\
\hline \multicolumn{5}{|l|}{ Comorbidity, \% (N) } \\
\hline HTN & 25.5 (38 399) & $21.6(26814)$ & $43.8(11585)$ & $<0.001$ \\
\hline CVD & $9.1(13635)$ & $7.4(9220)$ & $16.7(4415)$ & $<0.001$ \\
\hline DM & $15.6(23421)$ & $13.8(17$ 100) & $23.9(6321)$ & $<0.001$ \\
\hline CKD stages 3-5 & 4.1 (6098) & 3.2 (3918) & $8.2(2180)$ & $<0.001$ \\
\hline Stroke & 2.4 (3583) & $2.0(2458)$ & $4.3(1125)$ & $<0.001$ \\
\hline Asthma & 8.5 (12 792) & $8.1(10012)$ & $10.5(2780)$ & $<0.001$ \\
\hline COPD & $3.5(5206)$ & $2.9(3550)$ & $6.3(1656)$ & $<0.001$ \\
\hline Dementia & $0.6(920)$ & $0.5(600)$ & $1.2(320)$ & $<0.001$ \\
\hline SMI & 2.5 (3699) & $2.5(3094)$ & $2.3(605)$ & 0.510 \\
\hline Cancerף & $1.8(2719)$ & $1.5(1898)$ & $3.1(821)$ & $<0.001$ \\
\hline \multicolumn{5}{|l|}{ Covariates } \\
\hline $\mathrm{BPH}, \%(\mathrm{~N})$ & $3.5(5271)$ & $1.4(1787)$ & $13.2(3484)$ & $<0.001$ \\
\hline Prostatitis, \% (N) & $1.6(2405)$ & $0.9(1113)$ & 4.9 (1292) & $<0.001$ \\
\hline Tamsulosin use, \% (N) & $7.2(10825)$ & $3.2(4021)$ & $25.7(6804)$ & $<0.001$ \\
\hline Finasteride use, \% (N) & $2.4(3610)$ & $1.1(1419)$ & 8.3 (2191) & $<0.001$ \\
\hline \multicolumn{5}{|c|}{$\begin{array}{l}\text { Bold typeface indicates significance at } \mathrm{p} \leq 0.05 . \\
{ }^{*} \chi^{2} \text { between tested and untested groups. } \\
\text { tIndian, Pakistani, Bangladeshi or other Asian. } \\
\text { †11 } 462 \text { BMI values missing. } \\
\text { §Townsend score quintiles ( } 272 \text { scores missing). } \\
\text { IExcludes benign or malignant prostate cancer. } \\
\text { BPH, benign prostate hypertrophy; CKD, chronic kidney disease; COPD, chronic obstructive pulmonary disease; CVD, cardiovascular } \\
\text { disease; DM, diabetes mellitus; HTN, hypertension; PSA, prostate-specific antigen; SMI, significant mental illness. }\end{array}$} \\
\hline
\end{tabular}

or greater, rising to $17.5 \%$ by age $70-74$ years and $36.9 \%$ by age 90-94 years (figure 2B). The median (IQR) PSA values were $0.68 \mathrm{ng} / \mathrm{mL}(0.45-1.00)$ for $40-49$ years, $0.81 \mathrm{ng} / \mathrm{mL} \quad(0.50-1.40)$ for $50-59$ years, $1.20 \mathrm{ng} / \mathrm{mL}$ (0.65-2.30) for $60-69$ years, $1.63 \mathrm{ng} / \mathrm{mL}(0.80-3.30)$ for 70-79 years, $2.08 \mathrm{ng} / \mathrm{mL}(0.93-4.28)$ for $80-89$ years and $2.90 \mathrm{ng} / \mathrm{mL}(1.25-6.31)$ for $\geq 90$ years.
Association between PSA testing and age, ethnicity, social deprivation, BMI and comorbidity

PSA testing was positively associated with age. The adjusted OR of PSA testing in the 70-74 years age group was 7.34 (95\% CI 6.82 to 7.90$)$, compared to those baseline 40-44 years age group (table 2). Moreover, the odds of PSA testing increased in each age cohort peaking at 
Figure 2 (A, B) PSA testing prevalence, level and age. PSA, prostate-specific antigen.
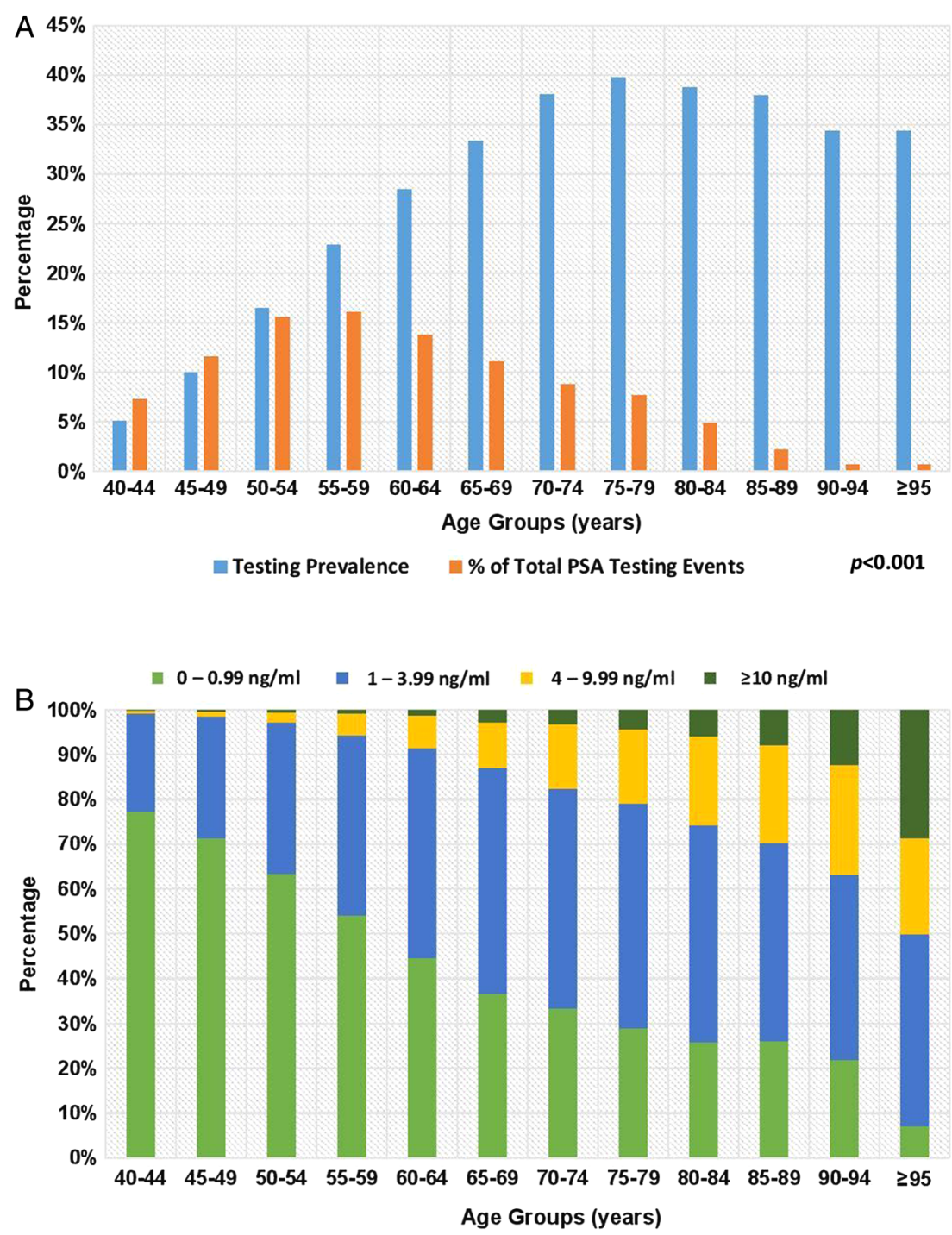

70-74 years and decreasing thereafter up to the $\geq 95$ years age group.

Compared to white patients, black (adjusted OR 1.78 (95\% CI 1.71 to 1.85)), mixed black and to lesser degree South Asian patients were significantly more likely to undergo PSA testing. This remained true for black and mixed black patients after further adjustment for included comorbidity clusters (data not shown), but the OR for South Asians become nonsignificant. Conversely, Chinese patients were significantly less likely to undergo PSA testing than white patients (table 2); there was minimal change in the OR after adjusting for included comorbidities (data not shown).

Increasing social deprivation was inversely associated with the odds of PSA testing (table 2).

Compared to patients of a normal BMI, obese patients were significantly more likely to undergo PSA testing (adjusted OR 1.29 (95\% CI 1.24 to 1.35$)$ ). The likelihood of PSA testing increased with each BMI class above normal weight and decreased in underweight patients (table 2).
PSA testing was significantly associated with cardiovascular comorbidity, especially with HTN. Dementia but not SMI showed an inverse association with PSA testing. There was a weak association between PSA testing and respiratory disease with no significant difference in testing in patients with a diagnosis of other cancer (table 2).

\section{DISCUSSION}

Summary

PSA testing prevalence was positively associated with increasing age, black, mixed black and South Asian ethnicity, increasing BMI and cardiovascular comorbidity. In contrast, PSA testing was inversely associated with Chinese ethnicity and greater social deprivation.

\section{Prevalence of PSA testing}

Based on our findings, the 1-year PSA testing prevalence in inner east London $(8.2 \%)$ was higher than the $6.2 \%$ reported in previous studies by Melia et $a l^{14}$ and Williams et al. ${ }^{15}$ However, both studies excluded older patients with an inclusion age criteria of 45-84 
Table 2 Association between PSA testing and age, ethnicity, social deprivation, BMI and comorbidity

\begin{tabular}{|c|c|c|c|c|}
\hline \multirow[b]{2}{*}{ Cofactor } & \multirow[b]{2}{*}{ Description } & \multicolumn{3}{|c|}{ PSA study group ( $\mathrm{N}=150481)$} \\
\hline & & $\begin{array}{l}\text { Unadjusted } \\
\text { OR }(95 \% \mathrm{CI})\end{array}$ & $\begin{array}{l}\text { Age-adjusted } \\
\text { OR }(95 \% \mathrm{CI})^{\star}\end{array}$ & $\begin{array}{l}\text { Age-adjusted and } \\
\text { covariate-adjusted } \\
\text { OR }(95 \% \mathrm{Cl}) \dagger\end{array}$ \\
\hline \multicolumn{5}{|c|}{ Prostate cancer risk factors } \\
\hline \multirow[t]{12}{*}{ Age } & $40-44$ years $(n=37668)$ & 1.00 (Reference) & NA & 1.00 (Reference) \\
\hline & $45-49$ years $(n=30792)$ & 2.04 (1.92 to 2.17$)$ & NA & 2.00 (1.88 to 2.12$)$ \\
\hline & $50-54$ years $(n=24982)$ & 3.66 (3.45 to 3.87 ) & NA & 3.44 (3.25 to 3.65$)$ \\
\hline & $55-59$ years $(n=18658)$ & 5.47 (5.17 to 5.79$)$ & NA & 4.81 (4.54 to 5.10$)$ \\
\hline & $60-64$ years $(n=12814)$ & 7.37 (6.94 to 7.82$)$ & NA & 5.91 (5.56 to 6.29$)$ \\
\hline & $65-69$ years $(n=8839)$ & 9.21 (8.64 to 9.81$)$ & NA & 6.71 (6.28 to 7.17$)$ \\
\hline & $70-74$ years $(n=6105)$ & $11.31(10.55$ to 12.11$)$ & NA & 7.34 (6.82 to 7.90$)$ \\
\hline & $75-79$ years $(n=5152)$ & $12.14(11.29$ to 13.05$)$ & NA & 6.86 (6.35 to 7.42$)$ \\
\hline & $80-84$ years $(n=3320)$ & $11.64(10.71$ to 12.65$)$ & NA & $6.02(5.49$ to 6.60$)$ \\
\hline & $85-89$ years $(n=1527)$ & $11.24(10.04$ to 12.59$)$ & NA & $5.41(4.77$ to 6.14$)$ \\
\hline & $90-94$ years $(n=522)$ & 9.63 (7.99 to 11.61$)$ & NA & 4.35 (3.54 to 5.35$)$ \\
\hline & $\geq 95$ years $(n=102)$ & 6.98 (4.51 to 10.81$)$ & NA & 3.25 (2.02 to 5.24$)$ \\
\hline \multirow[t]{9}{*}{ Ethnicity } & White $(n=61621)$ & 1.00 (Reference) & 1.00 (Reference) & 1.00 (Reference) \\
\hline & Black $(n=25$ 956) & 1.47 (1.41 to 1.52$)$ & 1.74 (1.68 to 1.81$)$ & $1.78(1.71$ to 1.85$)$ \\
\hline & $\begin{array}{l}\text { South Asian } ¥ \\
(n=39341)\end{array}$ & 0.94 (0.91 to 0.97$)$ & $1.13(1.09$ to 1.17$)$ & $1.08(1.04$ to 1.12$)$ \\
\hline & Chinese $(n=1363)$ & 0.65 (0.55 to 0.76$)$ & $0.66(0.56$ to 0.78$)$ & $0.67(0.56$ to 0.80$)$ \\
\hline & Mixed black $(n=2299)$ & 1.88 (1.71 to 2.06$)$ & 2.23 (2.02 to 2.46$)$ & 2.25 (2.03 to 2.50$)$ \\
\hline & Mixed Asian $\ddagger(n=235)$ & 0.97 (0.69 to 1.37$)$ & $1.23(0.86$ to 1.76$)$ & $1.21(0.83$ to 1.76$)$ \\
\hline & Other mixed $(n=608)$ & 0.65 (0.51 to 0.83$)$ & $1.03(0.80$ to 1.32$)$ & 1.00 (0.77 to 1.30$)$ \\
\hline & Other ethnicity $(n=5909)$ & $1.03(0.96$ to 1.10$)$ & 1.19 (1.11 to 1.29$)$ & 1.10 (1.02 to 1.19$)$ \\
\hline & Not defined $(n=13149)$ & $0.44(0.41$ to 0.48$)$ & $0.57(0.53$ to 0.61$)$ & $0.60(0.56$ to 0.65$)$ \\
\hline \multirow[t]{6}{*}{ BMI§ } & $\begin{array}{l}\text { Normal weight } \\
(n=47619)\end{array}$ & 1.00 (Reference) & 1.00 (Reference) & 1.00 (Reference) \\
\hline & Underweight ( $n=1558)$ & $0.96(0.84$ to 1.11$)$ & 0.79 (0.68 to 0.92$)$ & $0.82(0.70$ to 0.95$)$ \\
\hline & Overweight $(n=58787)$ & 1.26 (1.22 to 1.30$)$ & 1.19 (1.15 to 1.23$)$ & 1.18 (1.14 to 1.22$)$ \\
\hline & $\begin{array}{l}\text { Obese class I } \\
(n=22985)\end{array}$ & 1.49 (1.43 to 1.55$)$ & 1.31 (1.26 to 1.37$)$ & 1.29 (1.24 to 1.35$)$ \\
\hline & Obese class II $(n=6026)$ & 1.58 (1.48 to 1.69$)$ & 1.34 (1.26 to 1.44$)$ & 1.31 (1.22 to 1.41$)$ \\
\hline & $\begin{array}{l}\text { Obese class III } \\
(n=2044)\end{array}$ & 1.55 (1.39 to 1.73$)$ & $1.36(1.22$ to 1.52$)$ & $1.38(1.23$ to 1.55$)$ \\
\hline \multicolumn{5}{|l|}{ Non-risk factors } \\
\hline \multirow[t]{5}{*}{$\begin{array}{l}\text { Deprivation } \\
\text { quintiles }{ }^{\star \star}, \emptyset\end{array}$} & $\begin{array}{l}\text { Least deprived } \\
(n=32780)\end{array}$ & 1.00 (Reference) & 1.00 (Reference) & 1.00 (Reference) \\
\hline & Q2 (n=25 022) & 0.95 (0.91 to 1.00 & $0.97(0.92$ to 1.01$)$ & $0.96(0.92$ to 1.01$)$ \\
\hline & Q3 (n=25 802) & 0.93 (0.89 to 0.97$)$ & 0.95 (0.90 to 0.99$)$ & 0.94 (0.90 to 0.99$)$ \\
\hline & Q4 (n=28 637) & $0.92(0.88$ to 0.95$)$ & $0.90(0.86$ to 0.94$)$ & 0.89 (0.85 to 0.93$)$ \\
\hline & $\begin{array}{l}\text { Most deprived } \\
(n=37968)\end{array}$ & 0.85 (0.82 to 0.89$)$ & $0.85(0.82$ to 0.89$)$ & $0.83(0.80$ to 0.87$)$ \\
\hline \multirow[t]{11}{*}{ Comorbidity†† } & $\begin{array}{l}\text { Cardiovascular cluster } \\
(\mathrm{n}=53120)\end{array}$ & 2.92 (2.87 to 3.03 ) & $1.60(1.55$ to 1.65$)$ & $1.51(1.46$ to 1.56$)$ \\
\hline & HTN (n=38 399) & 2.83 (2.75 to 2.91$)$ & 1.53 (1.50 to 1.60$)$ & 1.49 (1.44 to 1.54$)$ \\
\hline & 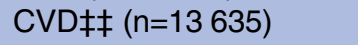 & 2.50 (2.40 to 2.60$)$ & 1.19 (1.14 to 1.24$)$ & $1.07(1.02$ to 1.12$)$ \\
\hline & DM $(n=23$ 421) & 1.97 (1.90 to 2.03$)$ & 1.22 (1.18 to 1.27$)$ & $1.16(1.12$ to 1.21$)$ \\
\hline & $\begin{array}{l}\text { CKD stage } 3-5 \\
(n=6098)\end{array}$ & 2.76 (2.61 to 2.91$)$ & $1.23(1.16$ to 1.31$)$ & 1.14 (1.06 to 1.21$)$ \\
\hline & Stroke $(n=3583)$ & 2.20 (2.05 to 2.36$)$ & $1.03(0.96$ to 1.11$)$ & $0.98(0.90$ to 1.06$)$ \\
\hline & $\begin{array}{l}\text { Respiratory cluster } \\
(n=16616)\end{array}$ & 1.55 (1.28 to 1.40$)$ & $1.18(1.13$ to 1.22$)$ & 1.08 (1.03 to 1.13$)$ \\
\hline & Asthma $(n=12792)$ & 1.34 (1.28 to 1.40$)$ & 1.25 (1.19 to 1.31$)$ & 1.15 (1.10 to 1.21$)$ \\
\hline & COPD $(n=5206)$ & 2.27 (2.14 to 2.41$)$ & 1.06 (1.00 to 1.13$)$ & 0.95 (0.89 to 1.02$)$ \\
\hline & $\begin{array}{l}\text { Mental health cluster } \\
(n=4572)\end{array}$ & 1.18 (1.09 to 1.27$)$ & 0.94 (0.87 to 1.02$)$ & $0.91(0.84$ to 0.99$)$ \\
\hline & Dementia $(n=920)$ & 2.52 (2.20 to 2.89 ) & $0.92(0.80$ to 1.05$)$ & $0.82(0.70$ to 0.96$)$ \\
\hline
\end{tabular}


Table 2 Continued

PSA study group ( $\mathrm{N}=150$ 481)

\begin{tabular}{|c|c|c|c|c|}
\hline \multirow[b]{2}{*}{ Cofactor } & \multirow[b]{2}{*}{ Description } & \multicolumn{3}{|c|}{ PSA study group ( $\mathrm{N}=150481)$} \\
\hline & & $\begin{array}{l}\text { Unadjusted } \\
\text { OR }(95 \% \mathrm{Cl})\end{array}$ & $\begin{array}{l}\text { Age-adjusted } \\
\text { OR }(95 \% \mathrm{Cl})^{\star}\end{array}$ & $\begin{array}{l}\text { Age-adjusted and } \\
\text { covariate-adjusted } \\
\text { OR }(95 \% \mathrm{Cl}) \dagger\end{array}$ \\
\hline & SMI $(n=3699)$ & $0.92(0.84$ to 1.00$)$ & 0.95 (0.86 to 1.04$)$ & $0.95(0.86$ to 1.04$)$ \\
\hline & $\begin{array}{l}\text { Other cancer§§ } \\
(n=2719)\end{array}$ & 2.06 (1.90 to 2.24$)$ & 1.13 (1.03 to 1.23$)$ & 1.02 (0.93 to 1.12$)$ \\
\hline
\end{tabular}

Bold typeface indicates significance at $\mathrm{p}<0.05$.

*Age adjusted in age groups 40-44, 45-49, 50-54, 55-59, 60-64, 65-69, 70-74, 75-79, 80-84, 85-89, 90-94 and $\geq 95$.

†Adjusted for age, BPH, prostatitis, tamsulosin or finasteride use.

†Indian, Pakistani Bangladeshi or other Asian.

$\S 11462 \mathrm{BMI}$ values missing.

१272 Townsend scores missing.

${ }^{*}$ Quintiles based on Townsend Scores -5 to +10

††Absence of comorbidity (individual or cluster) acts as reference group.

¥¥Includes IHD, PAD, AF and HF.

$\S \S$ Excludes benign or malignant prostate cancer.

$\mathrm{AF}$, atrial fibrillation; $\mathrm{BPH}$, benign prostate hypertrophy; CKD, chronic kidney disease; COPD, chronic obstructive pulmonary disease; CVD, cardiovascular disease; DM, diabetes mellitus; HF, heart failure; HTN, hypertension; IHD, ischaemic heart disease; PSA, prostate-specific antigen; SMI, significant mental illness.

and $45-89$ years, respectively. ${ }^{14}{ }^{15}$ Additionally, Williams et $a l^{15}$ reported higher PSA testing rates $(7.1-8.9 \%)$ in the southern UK general practices. Differences are likely to be multifactorial including north and south social deprivation differences. ${ }^{15}$ Based on reported 1 year PSA testing rates in the UK, there has been a modest $2 \%$ rise in testing rates from $6.2 \%^{14}{ }^{15}$ to the current rate of $8.2 \%$ in our study.

We observed a significant degree of variability in the PSA testing rate between practices, which is similar to previous findings, IQR 3.6-8.4\% (Williams et $a l^{15}$ ), and may be a reflection of differences in practice organisation, GP attitudes to testing or patient demographics. Yearly PSA testing rates also vary greatly between developed countries with greater testing in some EU countries (Germany 35\%), ${ }^{16}$ New Zealand $(22 \%)^{18}$ and a greater degree of testing in the USA $(57 \%){ }^{19}$ Hjertholm et $a l^{13}$ found no difference in prostate cancerspecific mortality between Danish practices with the highest and lowest relative levels of PSA testing, but there was a significant increase in prostate cancer diagnoses (mainly local disease), prostate biopsy and prostatectomy.

\section{PSA testing, level and age}

Similar to the findings of others, PSA testing rates increase with age, ${ }^{14-16}{ }^{18-20}$ and peak testing prevalence is among the patients aged 70-80 years old. ${ }^{14} 15{ }^{18-20} \mathrm{~A}$ third of those aged $\geq 70$ years have PSA levels $\geq 4$ $\mathrm{ng} / \mathrm{mL},{ }^{14} 15{ }^{21}$ which was consistent with our own findings.

\section{PSA testing and ethnicity}

In contrast to our study, Melia et $a l^{14}$ reported a decrease in PSA testing with increasing proportions of black and South Asian men. This finding was echoed by Gorday et $a l^{22}$ who found a decreased rate of PSA testing among black Canadian men. Further US studies have found little difference in PSA uptake between black and white patients. ${ }^{23-25}$ This is despite the increased incidence and mortality of prostate cancer among black men. ${ }^{4} 52627$ To the best of our knowledge, our study results are first to show higher rates of PSA testing among black men, which marks a positive change in testing behaviour potentially reflecting the increased underlying risk of prostate cancer and possibly driven by increased awareness of risk by patients and GPs. However, given that black men are at up to three times greater risk of developing prostate cancer, the raised ORs for testing found in our study do not sufficiently reflect the increased risk of prostate cancer in this group. The decreased PSA testing among Chinese men may reflect the reduced incidence and mortality risk of prostate cancer in the native Chinese population. ${ }^{28}$

\section{PSA testing and social deprivation}

The inverse relationship between socioeconomic status and PSA testing observed in this study has been reported in the $\mathrm{UK}^{1415}$ and internationally. ${ }^{16}{ }^{25}$ Purported reasons for this relationship are reduced access to health services in deprived areas and increased health awareness with greater patient-driven testing among less deprived patients. ${ }^{15} 16$ Prostate cancer mortality has also been found to be higher in more deprived populations. ${ }^{27}$ Although we used internal quartiles of deprivation and the studied London boroughs had high levels of deprivation, PSA testing should still be a patient-driven and clinician-driven process and efforts should to be made to reduce any socioeconomic disparities in testing.

\section{PSA testing and BMI}

Similar to our study findings, US studies by Fontaine $e t a l^{29}$ and Fowke $e t a l^{30}$ found a trend of increasing PSA testing with increasing BMI. A raised BMI is a proposed risk factor for prostate cancer, especially for advanced 
tumours. ${ }^{6}$ In this study, the increased PSA testing in obese patients more likely represents opportunistic testing in such patients who are more likely to have CVD associated with increased healthcare access. ${ }^{30}$

\section{PSA testing and comorbidity}

Fowke $e t a b^{30}$ found an increased rate of PSA testing in patients with comorbidity, particularly CVD (HTN, DM and high cholesterol) but no association with coronary heart disease or respiratory disease. Minor dissimilarities between the findings are likely to be the result of methodological differences such as their inclusion of a younger age range and adjustment for differing cofactors (Fowke $e t a l^{\beta 0}$ ).

A possible mechanism for the observed relationship between some comorbidities and PSA testing is that increased consultation rates and routine blood test monitoring for comorbidity could increase the opportunity to add PSA testing to existing monitoring tests. This hypothesis was also suggested by Fowke $e t a l^{30}$ who first reported for the positive association between CVD and PSA testing among obese men. Lack of association between PSA testing rates and other comorbidities may be related to lack of routine blood test monitoring in these comorbidities although this is unlikely to be the sole explanation since increased PSA screening rates were also seen in patients with asthma, a comorbidity not associated with blood test monitoring.

\section{Strengths and limitations}

The results of this study are reflective of current clinical practice as it features a large GP-registered population with an inclusive criteria featuring a broad age range with representation from various ethnicity groups, conducted over a 5-year period. Our study used routinely collected PSA testing data directly linked to computerised general practice systems largely avoiding data entry errors and reporting bias that occur with selfreported data. The use of a retrospective study design meant that PSA testing behaviour at the general practice level was not altered by the knowledge of an ongoing study.

Study limitations were that data on the PSA testing intent and whether patients were symptomatic or asymptomatic were not available. Similarly, we did not have data on whether PSA testing was initiated by the patient or GP. There are other drugs used on occasion for patients with prostatic symptoms or that may influence PSA levels that were not adjusted for in this study.

\section{CONCLUSIONS}

Based on our data from inner east London, 1-year PSA testing prevalence showed a modest increase from previous studies but was relatively low compared to other EU countries and the USA. Patients at higher risk of prostate cancer (older patients, black men and obese patients) had higher PSA testing rates; those at lower risk (patients of Chinese ethnicity) had lower testing rates. Independent of prostate cancer risk factors, patients living in more socially deprived areas had lower PSA testing rates and those with cardiovascular comorbidities had higher testing rates likely due to opportunistic testing. This study indicates that PSA testing may be influenced by prostate cancer risk factors and non-risk factors. In light of the current lack of evidence demonstrating a benefit in outcomes in testing asymptomatic men, positive associations with nonprostate risk factors may potentially increase the risk of invasive diagnostic procedures. Future studies should explore the intention for PSA testing in general practice, especially in relation to ethnicity, comorbidity and social deprivation.

Acknowledgements The authors thank all the patients and general practitioners for all their contributions that have made this study possible.

Contributors PN, MVH, MA, AD and SC conceived and refined the initial study design. PN and AD performed the background review. PN, MVH, RM and $\mathrm{SH}$ collated the study data and PN carried out the primary data analysis. $\mathrm{PN}, \mathrm{MVH}, \mathrm{MA}, \mathrm{RM}, \mathrm{SH}, \mathrm{AD}$ and $\mathrm{SC}$ were involved in the data interpretation and refined the primary study design and data analysis. PN drafted the initial manuscript. PN, MVH, MA, RM, SH, AD and SC refined the draft manuscript and approved the final submitted article.

Funding This study was funded by the Guy's and St Thomas' Hospital Charity (Fund 201).

Competing interests None declared.

Provenance and peer review Not commissioned; externally peer reviewed.

Data sharing statement No additional data are available.

Open Access This is an Open Access article distributed in accordance with the Creative Commons Attribution Non Commercial (CC BY-NC 4.0) license, which permits others to distribute, remix, adapt, build upon this work noncommercially, and license their derivative works on different terms, provided the original work is properly cited and the use is non-commercial. See: http:// creativecommons.org/licenses/by-nc/4.0/

\section{REFERENCES}

1. NICE. Prostate cancer: diagnosis and treatment. National Institute of Health and Clinical Excellence, 2014.

2. CRUK. Cancer Research UK. 2014. http://www.cancerresearchuk. org/cancer-info/cancerstats/types/prostate/

3. Bostwick DG, Burke HB, Djakiew D, et al. Human prostate cancer risk factors. Cancer 2004;101(Suppl 10):2371-490.

4. Chinegwundoh F, Enver M, Lee A, et al. Risk and presenting features of prostate cancer amongst African-Caribbean, South Asian and European men in North-east London. BJU Int 2006;98:1216-20.

5. Kheirandish $\mathrm{P}$, Chinegwundoh $\mathrm{F}$. Ethnic differences in prostate cancer. Br J Cancer 2011;105:481-5.

6. Maclnnis RJ, English DR. Body size and composition and prostate cancer risk: systematic review and meta-regression analysis. Cancer Causes Control 2006;17:989-1003.

7. Mackie A. Screening for prostate cancer: review against programme appraisal criteria for the UK National Screening Committee (UKNSC). UK National Screening Committee, 2010.

8. Burford DC, Kirby M, Austoker J. Prostate cancer risk management programme: information for primary care; PSA testing in asymptomatic men. NHS Cancer Screening Programme, 2009.

9. Pickles K, Carter SM, Rychetnik L. Doctors' approaches to PSA testing and overdiagnosis in primary healthcare: a qualitative study. BMJ Open 2015;5:e006367.

10. Schröder FH, Hugosson J, Roobol MJ, et al. Screening and prostate cancer mortality: results of the European Randomised Study of Screening for Prostate Cancer (ERSPC) at 13 years of follow-up. Lancet 2014;384:2027-35. 
11. Andriole GL, Crawford ED, Grubb RL III, et al. Prostate cancer screening in the randomized Prostate, Lung, Colorectal, and Ovarian Cancer Screening Trial: mortality results after 13 years of follow-up. J Natl Cancer Inst 2012;104:125-32.

12. Cooperberg MR, Lubeck DP, Meng MV, et al. The changing face of low-risk prostate cancer: trends in clinical presentation and primary management. J Clin Oncol 2004;22:2141-9.

13. Hjertholm P, Fenger-Grøn M, Vestergaard M, et al. Variation in general practice prostate-specific antigen testing and prostate cancer outcomes: an ecological study. Int J Cancer 2015;136:435-42.

14. Melia J, Moss S, Johns L. Rates of prostate-specific antigen testing in general practice in England and Wales in asymptomatic and symptomatic patients: a cross-sectional study. BJU Int 2004;94:51-6.

15. Williams N, Hughes LJ, Turner EL, et al. Prostate-specific antigen testing rates remain low in UK general practice: a cross-sectional study in six English cities. BJU Int 2011;108:1402-8.

16. Burns R, Walsh B, O'Neill S, et al. An examination of variations in the uptake of prostate cancer screening within and between the countries of the EU-27. Health Policy 2012;108:268-76.

17. Townsend $\mathrm{P}$, Phillimore $\mathrm{P}$, Beattie $\mathrm{A}$. Health and deprivation Inequality and the North. London: Croom-Helm, 1988.

18. Zuzana O, Ross L, Fraser $\mathrm{H}$, et al. Screening for prostate cancer in New Zealand general practice. J Med Screen 2013;20:49-51.

19. Sirovich BE, Schwartz LM, Woloshin S. Screening men for prostate and colorectal cancer in the United States: does practice reflect the evidence? JAMA 2003;289:1414-20.

20. D'Ambrosio GG, Campo S, Cancian M, et al. Opportunistic prostate-specific antigen screening in Italy: 6 years of monitoring from the Italian general practice database. Eur $J$ Cancer Prev 2010;19:413-16.

21. Melia J, Moss S. Survey of the rate of PSA testing in general practice. Br J Cancer 2001;85:656-7.

22. Gorday W, Sadrzadeh $\mathrm{H}$, de Koning L, et al. Association of sociodemographic factors and prostate-specific antigen (PSA) testing. Clin Biochem 2014;47:164-9.

23. Mariotto AB, Etzioni R, Krapcho M, et al. Reconstructing PSA testing patterns between black and White men in the US from Medicare claims and the National Health Interview Survey. Cancer 2007;109:1877-86.

24. Zhu $Y$, Sorkin JD, Dwyer D, et al. Predictors of repeated PSA testing among black and White men from the Maryland Cancer Survey, 2006. Prev Chronic Dis 2011;8:A114.

25. Scales $\mathrm{CD}$, Antonelli J, Curtis $\mathrm{LH}$, et al. Prostate-specific antigen screening among young men in the United States. Cancer 2008;113:1315-23.

26. Taksler GB, Keating NL, Cutler DM. Explaining racial differences in prostate cancer mortality. Cancer 2012;118:4280-9.

27. Ward E, Jemal A, Cokkinides V, et al. Cancer disparities by race/ ethnicity and socioeconomic status. CA Cancer J Clin 2004;54: 78-93.

28. Kazuto I. Prostate cancer in Asian men. Nat Rev Urol 2014;11:192-212.

29. Fontaine KR, Heo M, Allison DB. Obesity and prostate cancer screening in the USA. Public Health 2005;119:694-8.

30. Fowke JH, Signorello LB, Undwerwood W III, et al. Obesity and prostate cancer screening among African-American and Caucasian men. Prostate 2006;66:1371-80. 